\title{
Communication across cancer boundaries
}

\author{
Kaori Yagasaki, Hiroko Komatsu \\ Faculty of Nursing and Medical Care, Keio University, Japan \\ Correspondence: Kaori Yagasaki. Address: 35 Shinanomachi, Shinjuku-ku, Tokyo 160-8582, Japan. \\ Email: yagasaki@sfc.keio.ac.jp.
}

Received: December 27, 2012 Accepted: May 27, $2013 \quad$ Online Published: July 14, 2013

DOI : 10.5430/jnep.v3n10p159 URL: http://dx.doi.org/10.5430/jnep.v3n10p159

\section{Abstract}

Background: Cancer patients can be socially isolated and lonely. The general public still has negative attitudes toward cancer and cancer patients. It is important for cancer patients to have a supportive environment and to connect with other people.

Methods: We conducted a qualitative study with two focus group interviews of eight persons using a grounded theory approach to understand ordinary people's perceptions of cancer and cancer patients, and to explore their experience of interacting with the patients.

Results: This study revealed "Communication across cancer boundaries" as a core category with six themes: "negative assumptions," "social stigma," "communication boundaries," "transforming perceptions of cancer patients through interactions," "building communication competence," and "awakening empathy.” The ordinary people still had negative assumptions about cancer and cancer patients, leading to social stigma and creating communication boundaries. The experience of interaction with a cancer patient, however, altered their views on cancer patients, and reminded them of the need for communication competence to create a relationship with empathy.

Conclusions: The results of this study provided unique insights into ordinary people's views on cancer and cancer patients. Health care providers should understand how ordinary people perceive cancer patients, and provide education and they should provide information to both cancer patients and the general public. A society's greater understanding of cancer and cancer patients enables the society to provide an empathetic community where cancer is no longer seen as a taboo and stigmatized.

\section{Key words}

Communication, Empathy, Stigma, Ordinary people, Cancer patient

\section{I ntroduction}

Cancer survivors experience loneliness when they feel a crisis in their connection with others, and their cancer experience reminds them that everyone is alone in the world ${ }^{[1]}$. In a related study, socially isolated women had an increased risk of mortality after receiving a breast cancer diagnosis ${ }^{[2]}$.

Despite medical advances and improved outcomes, the general public still has negative attitudes toward cancer and cancer patients, including assumptions that cancer is an incurable disease, stereotypes about cancer patients, and discrimination 
toward individuals with cancer ${ }^{[3]}$. With extended survival, cancer patients also face new challenges, including coping with the fear of recurrence, the possibility of late and long-term adverse effects, and getting back to their normal daily lives ${ }^{[4]}$. Returning to work is increasingly important ${ }^{[5]}$, but deterioration in job satisfaction and even discrimination in the workplace have been reported by cancer survivors ${ }^{[6,7]}$. Poor communication between cancer patients and their employers has also been described ${ }^{[8-10]}$.

It is important for cancer patients to have a supportive environment and to connect with other people ${ }^{[3]}$. However, previous studies on communication with cancer patients mostly focused on family and health care providers, and it is still unclear how the people around cancer patients understand cancer and cancer patients. We conducted a qualitative study to understand ordinary people's perceptions of cancer and cancer patients, and to explore their experience of interacting with the patients.

\section{Subjects and methods}

\subsection{Research design}

To understand ordinary people's perceptions of cancer and cancer patients and to explore their experience of interacting with cancer patients, we conducted a qualitative study with focus group interviews using a grounded theory approach ${ }^{[11]}$.

\subsection{Participants and settings}

We recruited participants who were aged 20 and over, had no cancer history, and had the experience of interacting a cancer patient (their family, friend or co-worker had cancer) in the "cancer community" website ${ }^{[12]}$, the purpose of which is to establish an online community to support cancer patients (the website was developed and is operated by one of the authors, HK). Eight people (three men, five women) agreed to participate in the study by e-mail or fax. One of the eight participants could not attend the first focus group interview due to a schedule conflict, but the other seven participants attended two focus group interviews. The participants had a variety of backgrounds, including one unemployed man, an employer, three business persons, two self-employed persons and one part-timer.

\subsection{Data collection}

We conducted two focus group interviews at St. Luke's College of Nursing (Tokyo) between June and August, 2009. Each focus group interview lasted 2 hours. The nurse researcher (HK) took the role of facilitator using a semi-structured interview guide (What image do you have about cancer or cancer patients? What did you feel when you communicated with the cancer patient about his or her cancer? How did or do you want to interact with the cancer patient?), and recorded field notes from each interview. All interviews were conducted in Japanese, audiotaped and transcribed verbatim. The researcher translated themes and quotations which supported the themes into English.

\subsection{Analysis}

The data were analyzed according to grounded theory ${ }^{[11]}$. Open coding was achieved by deconstructing each interview sentence by sentence to generate the initial concept. Subcategories were derived from axial coding, and relating these subcategories led to categories. The core category was derived from relating all categories and subcategories.

\subsection{Rigor}

The rigor of the study was confirmed by credibility, dependability, confirmability, and transferability ${ }^{[13]}$. For credibility and dependability, two nurse researchers (HK and KY) reviewed the data to establish the codes and themes identified. After collecting the data from the first group interview, we discussed the quality and interpretation of the data for confirmation. We confirmed the data saturation after the second group interview. For confirmability, KY performed an 
analysis according to the grounded theory procedure ${ }^{[11]}$, and confirmed the results with HK. Transferability was reviewed and confirmed among the nurse researchers.

\subsection{Ethical considerations}

This study was approved by the Internal Review Board of St. Luke's College of Nursing. We explained the objective and outline of the study to all participants and obtained a written consent from each participant.

\section{Results}

The analysis revealed "communication across cancer boundaries" as a core category with six themes: "negative assumptions," "social stigma," "communication boundaries," "transforming perceptions of cancer patients through interactions,” "building communication competence,” and "awakening empathy.”

\subsection{Negative assumptions}

The participants had negative assumptions about cancer based on indirect information through the media, family and workplace. Most of the participants reported feeling that cancer was incurable, and linked to death.

"I have an image (of cancer) as a terminal disease," or "as painful or distressing."

People in Japan often avoid talking about death and dying, and since in Japan as in much of the world cancer has the reputation of always being fatal, it is culturally difficult to talk publicly about cancer.

“Well, it’s something like we shouldn't talk about.”

"Cancer is directly linked with death. So I see it something like taboo."

"Thinking or talking about death is taboo or difficult."

A stereotype of cancer patient is described by one of the participants: "The cancer patient is getting weaker and weaker before anyone realizes it. Even though the tumor was removed, it is still growing. It keeps coming back, and eventually death is waiting for her. That's the image (of a cancer patient)."

\subsection{Social stigma}

Since cancer is often linked to negative assumptions, cancer patients are vulnerable to social stigma. The participants who were an employer and a co-worker felt sorry for the cancer patient, while still getting their work done. The employer was concerned about financial management and efficiency, while the co-worker felt a burden to make up for the absence of the patient.

"When one person gets sick at workplace, I feel sorry for him, but as an employer, I hope that he quits soon because we are on a strict budget."(as an employer)

"When I have to do the extra work during the absence of that person, I feel sorry for her to be suffering from cancer, but at the same time, I am getting upset. Why should I make up for the absence of another employee?” (as a co-worker)

In addition, once he or she is labelled a cancer patient, the patient may be treated differently. Cancer often puts the patient's career at risk. 
"In a Japanese company, if a man is labelled a cancer patient, it's still true that he will lose his chance for promotion, or his name will be taken off a career making project.”

\subsection{Communication boundaries}

Patients and their families in Japan are still unwilling to talk about a cancer diagnosis. Other people are not sure whether they can talk about the cancer. The participants reported not knowing what to say and what to do around a cancer patient.

“Honestly, I don't know what I say to them (cancer patients).”

"I have to gauge what I should talk about with a cancer patient."

Because the participants are healthy, they feel sorry for cancer patients and even guilty. People are not sure whether they can share the feeling of cancer patient and feel uncomfortable about cancer. Consequently, they often avoid or change the subject of cancer. The hesitation makes communication with cancer patients difficult.

"I feel like I am on the living side, but the patient is on the dying side."

"I feel guilty to being (healthy) on the living side."

"I really don't know how I can communicate with a cancer patient."

\subsection{Transforming perceptions of cancer patients through interactions}

The participants thought that the cancer patient was so vulnerable that they could not talk about the cancer. However, once they actually interacted with the cancer patient, they were overwhelmed by the strength of the patient. They tried to find common ground, and they found it easier to communicate with the cancer patient than they thought.

"Recently, I had the second thoughts about my feelings. I didn't know what I should do for cancer patients, but it might not be right."

"The cancer patient might be waiting to be asked (about the disease)."

"The patient maybe wants to be asked (about her cancer experience) more."

"Not listening to the patient's story may make the patient isolated."

“Now I understand why cancer survivors often say they appreciated their cancer experience.”

\subsection{Building communication competence}

All of the participants were aware of their lack of cancer knowledge and communication skills. They wanted to be ready to help and support cancer patients so they wanted to build communication competence.

"We may become cancer patients too someday. I think that we have to have communication competency and listen to cancer patients.”

"If I am more competent, I will be able to accept it (the subject of cancer)."

The participants were also concerned about incorrect or misleading information about cancer, and they believed that it would be important that children learn about cancer in compulsory education to reduce the stigma attached to cancer.

"Eventually, education is important to distinguish correct information from wrong information (on the Internet).” 
"If children learn about cancer, not complicated matters, but something like the fact that one in three persons will suffer from cancer, and that it's common, such efforts may help us be familiar with cancer."

"Then, we will consider cancer less taboo."

\subsection{Awakening empathy}

With knowledge and communication competence, the participants believed that they would be able to communicate with cancer patients and be empathetic toward cancer patients. They wanted to develop a community where people talk openly and help each other.

"Satisfactory communication for everybody will follow from being knowledgeable. In-depth knowledge about cancer and common motivation will be the key."

"There is a great possibility that I or my parents or somebody who is close to me will suffer from cancer."

"In any case, I believe that talking person to person is important."

"Somebody close to the patient should be a person who supports him or her."

The participants emphasized the importance of open interactive communication, which fosters better interpersonal relationships.

"One of my friends has cancer but she is very open. The cancer patient and her family are all open.

Communication among family members is very good."

Even though the participants do not experience cancer, they realize they can share common views with the cancer patient. When people feel empathy for the patient, they try to help the patient. One of the participants described that helping others today would help themselves in the future.

“When I talk about it (cancer) to somebody, I will be cared for. You know, it’s a cycle.”

\section{Discussion}

This study revealed that there were cancer boundaries in communication between ordinary people and cancer patients. The ordinary people interviewed still had negative assumptions about cancer and cancer patients. The negative portrayal of cancer patients produced had uncomfortable feelings toward cancer patients, which impeded communication between the ordinary people and cancer patients. The negative assumptions about cancer patients also appeared to lead to social stigma in workplace. However, the experience of interaction with the cancer patient altered the interviewees' views about cancer patients, and reminded them of the need for communication competence to create a relationship with empathy.

Before discussing the findings, several limitations of the study should be discussed. Since all of the participants had the real-life experience of interacting with a cancer patient, they might be more likely to be interested in communication with cancer patients than those without the actual experience. This study was based on the grounded theory approach, but we did not conduct a theoretical sampling. The sample size was small in this study because only eight persons replied to our web-based recruitment, and one of them could not attend the first focus group interview due to a schedule conflict. Further studies are needed to increase the number of participants in consideration of demographics and family history of cancer. Because of the nature of the focus group interview, the results may be influenced by the opinions of others.

Ordinary people still have a notion that cancer is an incurable disease leading to death, even though cancer is becoming a curable disease. These negative assumptions and stereotypical views about cancer patients lead to social stigma, creating 
boundaries between "normals" and "outsiders," labelling "them," the stigmatized group, from "us” [14, 15]. Health-related stigma links to social disqualification, limited opportunities, and negative change in identity ${ }^{[16]}$. Cancer patients often have fears of embarrassing or upsetting others, being the subject of gossip, or being stigmatized ${ }^{[10]}$. Consequently, cancer patients and families often conceal cancer diagnoses ${ }^{[3]}$. People in non-Western countries are more likely to consider cancer a taboo subject, and people in those countries seldom discuss cancer publicly ${ }^{[3,17]}$.

The participants in the present study described the differences between ordinary people and cancer patients as "the living side" and "the dying side," and they reported feeling sorry for cancer patients and feeling guilty about being healthy themselves. They separated the cancer patients from themselves, while feeling guilty about doing so, but at the same time, they wanted to know the feelings of patients. These ambivalent feelings can turn into offerings of support. In fact, after interacting with the cancer patient, the interviewees had different views on cancer patients; they realized that such patients are not as vulnerable as they thought, and they were willing to be in contact with cancer patients. "Contact" refers to all interactions between the public and persons affected, with the specific objective to reduce stigmatizing attitudes. Contact can be either direct and face-to-face, or indirect (e.g., through the media) ${ }^{[14]}$.

A stigma is related to a deficit of knowledge ${ }^{[16]}$. Ordinary people often seek cancer information on the Internet, but the reliability of Internet information has been identified as a problem ${ }^{[18]}$. The participants in the present study believed that school education would contribute to improving cancer literacy and reducing the social stigma. Understanding of the disease led to better support ${ }^{[9]}$. In a society with better knowledge, people will not feel like they have to conceal a cancer diagnosis, and communication with cancer patients becomes more open and easier.

People feel loneliness when they feel apart from, yet in need of, others ${ }^{[1]}$. Deficiencies of social ties expose cancer patients to the stress of loneliness, and put them at risk of a greater impact of the stressors encountered in daily life ${ }^{[19]}$. If patients have high levels of social support, they are not hopeless or lonely ${ }^{[19,20]}$. An earlier study suggested that patient communication skills training can be applied to workplaces, so that patients with cancer or other long-term diseases can discuss the impact of treatment on their work performance and the needs with employers ${ }^{[8]}$. Employers and co-workers also need to learn how to communicate with cancer patients. Supportive colleagues can reduce the feelings of social isolation experienced by cancer patients ${ }^{[10]}$, and help them feel emotionally supported and adjusted to work ${ }^{[9]}$. Seeking to understand a cancer patient, the interviewees in the present study addressed the need for communication competence. Family members also have important ties with cancer patients and should be educated and supported by health care providers ${ }^{[21]}$.

There are implications of the present study for health care providers. Health care providers should recognize that there are cancer boundaries in the communication between ordinary people and cancer patients, and they should educate the general public that overcoming these boundaries could produce new social capacity. Social support is essential to prevent cancer patients from becoming hopeless or lonely members of a society. Educational tools should be developed and promoted for ordinary people to raise cancer literacy and to prevent stigma. Since this study showed the importance of interactions between cancer patients and ordinary people, effective programs need to be developed for sharing information and experiences. Health care providers need to create supportive environments to develop an empathetic community where the patients and ordinary people help each other.

\section{Conclusions}

Although the results of this study were derived from a small sample, the participants were ordinary people with a variety of backgrounds, and they therefore provided unique insights into ordinary people's views on cancer and cancer patients. More research is clearly needed on this topic, including the development of educational tools and communication programs. Given that many more cancer survivors are expected, every society should support cancer patients during their 
treatment and survivorship. A greater understanding of cancer patients and the provision of supportive environments for them will enable us to develop an empathetic community where cancer is no longer seen as a taboo and stigmatized.

\section{Acknowledgements}

This study was supported by the Japan Society for the Promotion of Science KAKENHI Grants-in-Aid for Scientific Research (A), Number 19209066 (Chief investigator: Hiroko Komatsu).

\section{Conflicting interest}

The authors report no conflicts of interest.

\section{Reference}

[1] Rosedale M. Survivor loneliness of women following breast cancer. Oncol Nurs Forum. 2009 Mar; 36(2): 175-83. http://dx.doi.org/10.1188/09.ONF.175-83.

[2] Kroenke CH, Kubzansky LD, Schernhammer ES, Holmes MD, Kawachi I. Social networks, social support, and survival after breast cancer diagnosis. J Clin Oncol. 2006 Mar 1; 24 (7): 1105-11.

[3] Cho J, Smith K, Choi EK, Kim IR, Chang YJ, Park HY, et al. Public attitudes toward cancer and cancer patients: a national survey in Korea. Psychooncology. 2012 Feb; 16. http://dx.doi.org/10.1002/pon.3041.

[4] Arora NK, Finney Rutten LJ, Gustafson DH, Moser R, Hawkins RP. Perceived helpfulness and impact of social support provided by family, friends, and health care providers to women newly diagnosed with breast cancer. Psychooncology. 2007 May; 16(5): 474-86.

[5] Spelten ER, Sprangers MA, Verbeek JH. Factors reported to influence the return to work of cancer survivors: A Literature Review. Psychooncology. 2002 11: 124-31.

[6] Amir Z, Moran T, Walsh L, Iddenden R, Luker K. Return to paid work after cancer: A British experience. J Cancer Surviv. 2007 Jun;1(2):129-36. http://dx.doi.org/10.1007/s11764-007-0021-2.

[7] Park JH, Park JH, Kim SG, Lee KS, Hahm MI. Changes in employment status and experience of discrimination among cancer patients: findings from a nationwide survey in Korea. Psychooncology. 2010 Dec; 19(12): 1303-12. http://dx.doi.org/10.1002/pon.1694.

[8] Brown RF, Owens M, Bradley C. Employee to employer communication skills: balancing cancer treatment and employment. Psychooncology. 2011 Dec 12. http://dx.doi.org/10.1002/pon.2107.

[9] Yarker J, Munir F, Bains M, Kalawsky K, Haslam C. The role of communication and support in return to work following cancer-related absence. Psychooncology. 2010 Oct; 19(10): 1078-85. http://dx.doi.org/ 10.1002/pon.1662.

[10] Tiedtke C, de Rijk A, Dierckx de Casterlé B, Christiaens MR, Donceel P. Experiences and concerns about 'returning to work' for women breast cancer survivors: a literature review. Psychooncology. 2010 Jul; 19(7): 677-83. http://dx.doi.org/ 10.1002/pon.1633.

[11] Strauss A, Cobin J. Basics of qualitative research: grounded theory procedures and techniques. Newbury Park, CA: Sage.1990.

[12] Gancommunity. Available from: http://www.gancommunity.com/

[13] Guba E, Lincoln YS. Competing paradigms in qualititative research. In: Denzin NK, Licon YS, eds. Handbook of Qualitative Research. Thousand Oaks, CA: Sage; 1994:105-17.

[14] Heijnders M, Van Der Meij S. The fight against stigma: An overview of stigma-reduction strategies and interventions. Psychol Health Med. 2006 Aug; 11(3): 353-63.

[15] Link BG, Phelan JC. Stigma and its public health implications. Lancet [Internet]. 2006. 367: 528-9. Available from: www.thelancet.com. 2006 Feb 11(367).

[16] Cataldo JK, Slaughter R, Jahan TM, Pongquan VL, Hwang WJ. Measuring stigma in people with lung cancer: psychometric testing of the cataldo lung cancer stigma scale. Oncol Nurs Forum. 2011 Jan; 38(1): E46-54. http://dx.doi.org/10.1188/11.ONF.E46-E54.

[17] Zamanzadeh V, Rahmani A, Valizadeh L, Ferguson C, Hassankhani H, Nikanfar AR, et al. The taboo of cancer: the experiences of cancer disclosure by Iranian patients, their family members and physicians. Psychooncology. 2011 Dec 2. http://dx.doi.org/10.1002/pon.2103.

[18] Muusses LD, van Weert JC, van Dulmen S, Jansen J. Chemotherapy and information-seeking behaviour: characteristics of patients using mass-media information sources. Psychooncology. 2012; 21(9): 993-1002. http://dx.doi.org/ 10.1002/pon.1997. 
[19] Yildirim Y, Kocabiyik S. The relationship between social support and loneliness in Turkish patients with cancer. J Clin Nurs. 2010 Mar; 19 (5-6): 832-9. http://dx.doi.org/ 10.1111/j.1365-2702.2009.03066.x.

[20] Pehlivan S, Ovayolu O, Ovayolu N, Sevinc A, Camci C. Relationship between hopelessness, loneliness, and perceived social support from family in Turkish patients with cancer. Support Care Cancer. 2012 Apr; 20 (4): 733-9. http://dx.doi.org/10.1007/s00520-011-1137-5.

[21] Tan M, Karabulutlu E. Social support and hopelessness in Turkish patients with cancer. Cancer Nurs. 2005 May-Jun; 28(3): 236-40. 